925 autosomal dominant inheritance of alopecta congenita WITH KERATOSIS PALMO-PLANTARIS. Lytt I. Gardner. Department of Pediatrica, SUNY, Upstate Medical

Center, Syracuse, New York.

The syndrome complex of congential (total) alopecia, keratosis of palms and soles and dystrophy of nails is a rare mutation with an autosomal dominant pattern of Inheritance. Only one other report could be found (Stevanov1c, Acta Genet. $9: 127,1959$ ). In the previously described kindred, as well as in the present one, there was variable expression of the 11sted traits. In the presont kindred there were three Individuals with the full syndrome and five with partial or no alopecta, yet exh1biting keratosis of palms and soles and nall dystrophy. The proposita had total alopecia, including absence of eyebrows, eyelashes and sexual hair. She perspired normally and had no dental abnormalities. Na1ls were ridged and dystrophic, and palms and soles were covered with heavy keratosis having an opalescent orange-pink color. Intelligence was normal. Karyotype on peripheral leucocytes was $46, x x$. Banding studies are incomplete.

Similar variability in expression of tratts is seen in other vertically inherited syndromes such as pseudo-pseudohypoparathyrold1sm and Gardner's syndrome, and may represent unequal crossing over with duplication or triplication of loci in subsequent generations. An animal model is represented by the situation at the Bar locus in Drosoph1la (region 16-A of the X-chromosome). Unequal crossing over results in duplication or triplication of region 16-A, with triple-Bar presenting a more abnormal phenotype tive enough to test this hypothesis in man rematns to be

\section{THE EFFECTS OF MODERATE ALCOHOL CONSUMPTION DURING} PREGIAANCY ON FETAL GROWTH AND MORPHOGENESIS
James $W$. Hanson, Ann P. Streissguth, David W. Smith
of Washington, Schoof of Medicine, Pedratrics, Seattl Untversity of Washington, School of Medicine, Pedratrics, Seattle Although heavy alcohol consumption during pregnancy has been studies have not indicated the magnitude of risk which may be part of a larger study of pregnancy and health in 1529 mothers information on study of pregnancy and health 1529 mothers, information on maternal alcohol intake during the month preceding pregnancy and during the first five months of pregnancy, was collected. At the time of delivery, 97 infants born to women who drank an average of one ounce of ethanol or more per day, in the month prior to pregnancy or during the first five months of pregnancy, were selected. For each infant, a control infant whose alcohol was selected. Each reefluation without knowledge as to maternal drinking history. Of eleven infants judged clinically to show signs compatible with a prenatal effect of alcohol on growth and morphogenesis, nine were found to be from the high risk drinking group. Two of these infants, from the heaviest drinking mothers, had the fetal alcohol syndrome. The other seven infants, who showed lesser alterations of growth and morphogenes is, were born to women who drank moderate amounts of alcohol during the earliest part of pregnancy. Most of these women were found to be "binge" drinkers. These results indicate that moderate levels of alcohol intake during early pregnancy, may result in significant alterintake during early pregnancy, may result in signif icant alter-
ations of growth and morphogenesis in the fetus. "Binge" drink-
ing may represent an additional risk factor for the fetus.

927 SMALL MOLBCULAR WEIGITI HYDPOXYPROLINE-CONTAINING COYPOUNDS IN THE DEVELOPING MOUSE LIMB. LEW IS B. Holmes and Robert L. Trelstad, Mass. Cen. Tosp.

We have found 3 small molecular weight hydroxyproline (OFPro)containing compounds that are abundant in the developing mouse 1imb. The amino acid OfPro is customarily related to thepresence of collagen and elastin, molecules in the extracellular matrix that contain OHPro. Colls cannot incorporate free OHPro directly into collagen during synthesis; instead OHPro is formed by the post-translational hydroxylation of polypeptide-bound proline. In fibroblast cultures (J. Cell Sci. 12:217, 1973) most of the labeled OHPro made from proline is a free amino acid or in a small polypeptide.

We have cultured developing limbs from day 10 to 14 enbryos with C14-prol ine for $4 \mathrm{hrs}$. Small and large molecular weight fractions were obtained by chromatography on Sephadex $6-25$. The amount of C14-OHP wo was determined on an amino acid analyzer column. Over 808 of the C14-OIPro was in the small molecular weight fractions and included trans-4-OIPro, Cis-4-alPro and trans-3-0l Pro. These compounds were also produced in the presence of $\alpha \alpha^{\prime}$-dipyridyl, which inhibits the known hydroxylation enzyme. The presence of Cis-4-OHPro is a surprise as it prevents the formation of a stable collagen helix. This compound has never been isolated from mammalian tissues. Trans-3-0tPro is abendant in type IV collagen, the most common source of which is basement mentranes. The role (if any) of these 3 small molecular
weight otj-pro compounds in development remains to be eluciated. supported by NIH Grants 1 DDO9689 and HE 18714 .
928 FURTHER HETEROGENEITY IN LETHAL NEONATAL SHORT-LTMBED DWARPISM. Horton, William A.. Rimoin, David L., Hol1ister, David W.. and Lachman, Ralph s. UCLA-Harbor General Hospital, Division of Medical Genetics, Torrance, Calif. In recent years the extent of the heterogeneity within lethai neonatal short limbed dwarfism has become apparent, with the deIineation of numerous distinct syndromes such as thanatophoric dwarfism, achondrogenesis and the short rib polydactyly syndromes. Utilizing a combined clinical, radiologic, histologic and biochemical approach, we have observed further heterogeneity within this group of disorders. For example, we feel we can distinguish at least 3 distinct disorders in what has been called "thanatophoric" dwarfism, by histological and biochemical criteria. One group of patients is recognized by the kleeblattschadel skull deformity. They differ both radiologically and in the histologic appearance of their growth plates from pationts not manifosting this deformity. In this latter group, 2 additional disorders can be distinguished by specific growth plate histopathology and blochemical abnormalities observed on whole chain electrophoresis of collagon isolated from resting cartilage. Similarly, 2 distinct varietios of achondrogenesis can be clearly separated by radiologic and histopathologic criteria. The short rib polydactyly syndromes were originally divided into the Majewski and Saldino-Noonan type on the basis of radiologic criteria. We feel that the latter type can be further subdivided into 2 distinct entities. These studies demonstrate that the true heterogeneity of this group of disorders eity will likely to be appreciated, and that

\section{DETEEMINANTS OF GRONTH IN PATIENTS WTTH VENTRICULAR} SEPTAL DEPECT. Robert Lovy, Amnon Posenthel, Olli School, Cilldren's Hospital Medical Center, Dopartment of Cardiology and Epidomiology, Boston, Mass.

Grovth status was assessed in 1210 pationte (pts) with ventricular septal defect (VSD) participating in the Cooperative study on the Mntural History of Congenital Haart Disease. Height (Ht) and weight (Wt) maturation wore compared to the now National conter for Health Statistics norms. A total of 793 pts were managed modical1y, 104 underwent successful surgical renair, and 223 were surgically nalliated. ihean follow-up pariod was 6.4 yearn (range 4 to 8 vears). On Initial assessment 77.01 of $n t=$ wore below normal mod-

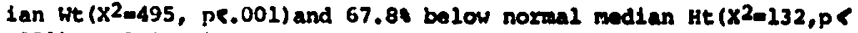
.001). Multivariate analysis revealed major algnielcant doterminants of $H$ t at initial assessivent and aftor medical or surqical managoment to be birth wt $2.5 \mathrm{~kg}(t-w-6.5, p(.001)$, pulmonary/aystemic pressure ratio(t-m-4.8,0<. 001), presence of extracardiac con ronital anomalios (ECA) $(t=-3.4, p<.001)$, and advaneing age $(t=+3.3$, pe. 001). Determinants of were similax to those for it exoupt for the edditional influence of pulmonary/aystamic ftow (op/Qs) ratio $(t=-4,5, p(001)$. Hean He incroabed to the oxtent independently of management, but remalned eubnormal (t--8.9,pP.001). By contrast wt status showed significantly areater gains aftor repalx ( $t=+2.5$, pe. 01) with improvement to normal mean itt. Wo conclude that growth in pts with VSD is strongly influenced by intra uterine growth, presence of ECN and hemodynamic abnormallties. Correction of abnormal hemodynamics improves groivth if other re-

\section{THE MECKELGRUBER (MGS)/ULLRICH.FEICHTIGER (UFS). SYN.} DROME: ANTEMORTEM HORMONAL STUDIES, S.L. Maby, H.L. Vallet,

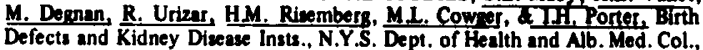
Dept. Peds. Albany, N.Y.

Controversy exists regarding differentiation of the MGS and UFS. Because of variation in features in MGS, and question of the existence of UFS, a better definition of the hormonal pathophysiology should permit precise delineation. We have studied a neonate with the 'fol. lowing anatomic defects: occipital protuberance (increased transillumination), coronal aynos. tosis, low set ears, Brushfeld spots, bulbous nose, microenathis, bilaternil hydronephroets 25 $\mathrm{cm}$ hooded phallus, 10 hypospadias and absent scrotum; a postertiorly displicesed anus, loose akin. joint contractures, aimian cresses, bilateral tulipes equinoverus, bilateral duplication of the first

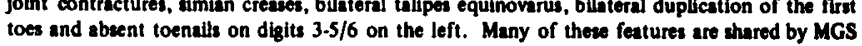
and UFS. Chromosomal analysis was normal, $46, X Y$.

Endocrinological investigations included thymoid studies: absent epiphyseal centers. $T_{4} 1.6$. $\mathrm{FT}_{4} 0.5 \mathrm{ng} / \mathrm{dl}, \mathrm{TSH}>160 \mu \mathrm{\mu} / \mathrm{ml}$, antithyroid antibodies-neg; pituitarv-airenal axis: urinary steroids (mg/da) $17 \mathrm{KS}<0.44 .170 \mathrm{OH}<0.5$. P'triol < 0.2. ACTH-pending:pituitran-gmoatal axis: FSH $10.4 \mathrm{mlu} / \mathrm{ml}$, LH $32.6 \mathrm{ml} / \mathrm{ml}$. lestosterone $17 \mathrm{ng} / \mathrm{dl} ; \mathrm{llGH}>50 \mathrm{ng} / \mathrm{ml}$ : no abnormalities of $\mathrm{Ca} / \mathrm{P}$ or glucose homeostasis. These studies demonstrate primary thyroidal, guncalal, and probably adrenal fallure. Previous anatomic descriptions of tie endorine abnormalitites in there syndromes have implied functional relationslips with an inability to define 10 vs 20 hormonal dysfunction.

The morphological abnormalities described leere are consistent with UFS and lend support to It being a distinct nosologic entity. As a result of this study end-ongan fallure shouth mow' be included as a diagnostic feature of the UFS. The infant expired before other hurmonal studies were completed. Necropsy findings will be discussed. 